\title{
Enfermedad celiaca asociada a síndrome antifosfolípido
}

\author{
O. Jorge, A. Jorge y G. Camus \\ Servicio de Gastroenterología. Hospital Español de Mendoza. Argentina
}

\section{RESUMEN}

Introducción: la enfermedad celiaca puede asociarse a patologías de etiología inmunológica. Presentamos su asociación con síndrome antifosfolípido.

Caso 1: mujer, 26 años, diagnosticada de enfermedad celiaca. Seis meses después queda embarazada, presentando muerte fetal. Al año siguiente nuevo embarazo. Anticuerpos anticardiolipina IgG: $20 \mathrm{GPL} \mathrm{U/ml} \mathrm{(valor} \mathrm{normal} \mathrm{<} \mathrm{11)} \mathrm{y} \mathrm{anticardiolipina}$ IgM: 9 MPL U/ml (v.n. < 10). Estudio hematológico sin otras alteraciones protrombóticas. Medicada con ácido acetilsalicílico presenta embarazo normal.

Caso 2: mujer, 48 años, diagnosticada de enfermedad celiaca, presentó trombosis de extremidad inferior e infarto renal. Examen hematológico sin alteraciones protrombóticas (no se dosaron anticuerpos antifosfolípidos). Año y medio después trombosis de dedo de mano. Anticuerpos anticardiolipina IgG: 10 GPL (v.n. < 13) y anticardiolipina IgM: 35 MPL (v.n. < 12).

Caso 3: mujer, 38 años, diagnosticada de enfermedad celiaca. Posteriormente dos abortos espontáneos y un accidente isquémico transitorio cerebral. Actualmente está en el sexto mes de embarazo, anticuerpos anticardiolipina IgM $75 \mathrm{MPL} / \mathrm{ml}$ (v.n. hasta 20) y anticardiolipina IgG en valores normales. El estudio hematológico no evidenció otras alteraciones protrombóticas.

Discusión: el síndrome antifosfolípido se caracteriza por trombosis arterial y venosa y muerte fetal espontánea. Su asociación a enfermedad celiaca ha sido descrita en pocos casos. La enfermedad celiaca se asocia a muerte fetal espontánea, pudiéndose hipotetizar que el síndrome antifosfolípido podría ser una de las causas de este fenómeno.

Palabras clave: Enfermedad celiaca. Síndrome antifosfolípido. Anticuerpos anticardiolipina. Muerte fetal espontánea.

\begin{abstract}
Introduction: celiac disease may be associated with pathologies of immune etiology. We present its association with antiphospholipid syndrome.

Case 1: a 26-year-old female was diagnosed with celiac disease. Six months later she became pregnant, and experienced fetal death. The following year she became pregnant again. IgG anticardiolipin antibodies: $20 \mathrm{GPL} \mathrm{U} / \mathrm{ml}$ (normal value $<11$ ), and IgM anticardiolipin antibodies: $9 \mathrm{MPL} \mathrm{U/ml} \mathrm{(n.} \mathrm{v.} \mathrm{<} \mathrm{10).} \mathrm{Hemato-}$ logical tests were otherwise uneventful. Medicated with acetylsalicylic acid she had a normal pregnancy.

Case 2: a 48-year-old female diagnosed with celiac disease presented with thrombosis in her left lower limb and renal infarction. Hematological tests showed no prothrombotic alterations (antiphospholipid antibodies were not measured). A year and a half later she had thrombosis in a finger of her hand. IgG anticardiolipin antibodies: 10 GPL (n. v. < 13), and IgM anticardiolipin antibodies: 35 MPL (n. v. < 12).

Case 3: a 38-year-old female was diagnosed with celiac disease. Some time later she experienced two spontaneous abortions and a transient ischemic cerebral attack. Nowadays, she is in her sixth month of pregnancy. IgM anticardiolipin antibodies: $75 \mathrm{MPL} / \mathrm{ml}$ (n. v. up to 20), and IgG anticardiolipin antibodies within normal values. Hematological tests revealed no other prothrombotic alterations.

Discussion: antiphospholipid syndrome is characterized by arterial and venous thrombosis, and spontaneous fetal death. Its association with celiac disease has been described in few cases. Celiac disease is associated with spontaneous fetal death; consequently, we hypothesize that antiphospholipid syndrome may be one of the causes for this event.
\end{abstract}

Key words: Celiac disease. Antiphospholipid syndrome. Anticardiolipin antibodies. Spontaneous fetal death.

Jorge O, Jorge A, Camus G. Enfermedad celiaca asociada a síndrome antifosfolípido. Rev Esp Enferm Dig 2008; $100: 102-103$.

\section{INTRODUCCIÓN}

Recibido: 05-09-07.

Aceptado: 14-09-07.

Correspondencia: Oliver A. Jorge. C/ Videla Castillo, 1996. 5500 Mendoza, Argentina.e-mail: arturo.jorge@ speedy.com.ar
La enfermedad celiaca puede asociarse a numerosas patologías de etiología inmunológica como diabetes mellitus insulino-dependiente, tiroiditis autoinmune, lupus eritematoso sistémico, síndrome de Sjögren, polimiositis, 
miastenia gravis y artritis reumatoidea (1). Presentamos la asociación de enfermedad celíaca con síndrome antifosfolípido.

\section{CASO 1}

Paciente mujer, edad 26 años, diagnosticada de enfermedad celiaca con anticuerpos antitransglutaminasa $73 \mathrm{U}$ (valor normal hasta 10) y biopsia duodenal con enteropatía con atrofia vellocitaria severa (grado III). Presentó buena evolución con dieta libre de gluten, desapareciendo diarrea y mejorando estado nutricional. Seis meses después la paciente queda embarazada, presentando muerte fetal a las 36 semanas. Al año siguiente presenta nuevo embarazo. Se determinan anticuerpos anticardiolipina IgG: $20 \mathrm{GPL} \mathrm{U} / \mathrm{ml}$ (v.n. < 11) y anticardiolipina IgM: $9 \mathrm{MPL} \mathrm{U/ml} \mathrm{(v.n.} \mathrm{<} \mathrm{10).} \mathrm{El} \mathrm{estudio} \mathrm{hematológico} \mathrm{no} \mathrm{evi-}$ denció otras alteraciones protrombóticas. Se la medica con ácido acetilsalicílico a dosis de 200 mg/día presentando embarazo y nacimiento por cesárea normales.

\section{CASO 2}

Paciente mujer, edad 48 años, diagnosticada de enfermedad celiaca con anticuerpos antitransglutaminasa mayor de $100 \mathrm{U} / \mathrm{ml}$ (v.n. hasta 10) y biopsia duodenal con acentuada atrofia vellositaria (grado III). Se indica dieta libre de gluten, presentó trombosis de extremidad inferior izquierda e infarto renal izquierdo diagnosticado por RMN. Se decide anticoagulación con acenocumarol. Al examen hematológico, fueron normales los valores de antitrombina III, proteína $\mathrm{C}$, proteína $\mathrm{S}$ y factor $\mathrm{V}$ Leiden. Se suspende acenocumarol. Año y medio después la paciente presenta trombosis de dedo medio de mano derecha, por lo que se reinstaura acenocumarol. Se realizan anticuerpos anticardiolipina IgG: 10 GPL (v.n. < 13) y anticardiolipina IgM: 35 MPL (v.n. < 12).

\section{CASO 3}

Paciente mujer, edad 38 años, diagnosticada de enfermedad celiaca con anticuerpos antitransglutaminasa $46 \mathrm{U}$ (v.n. hasta 5) y biopsia duodenal compatible con enfermedad celiaca. Posteriormente presenta dos abortos espontáneos y un accidente isquémico transitorio cerebral. Actualmente cursa sexto mes de embarazo con anticuer- pos anticardiolipina IgM $75 \mathrm{MPL} / \mathrm{ml}$ (v.n. hasta 20) y anticardiolipina IgG en valores normales. Estudio hematológico no evidenció otras alteraciones protrombóticas. Sigue tratamiento con heparina subcutánea y dieta libre de gluten.

\section{DISCUSIÓN}

El síndrome antifosfolípido se caracteriza por trombosis arterial y venosa y muerte fetal espontánea (posiblemente por trombosis de los vasos placentarios). Existen varios anticuerpos antifosfolípido como los anticardiolipina y los antib2-glicoproteína dirigidos contra las paredes vasculares. Puede ser primario o asociarse a otras patologías como enfermedades del tejido conectivo o enfermedad inflamatoria intestinal idiopática (2). Su asociación a enfermedad celiaca ha sido descrita en pocos casos, asociándose a trombosis portal (3), hiperplasia nodular regenerativa (4), necrosis cutánea (5) y miocardiopatía dilatada (6). La enfermedad celiaca se asocia a muerte fetal espontánea (7), pudiéndose hipotetizar que el síndrome antifosfolípido podría ser una de las causas de este fenómeno. En conclusión, podemos decir que la enfermedad celiaca puede asociarse a síndrome antifosfolípido, con riesgo de trombosis, infartos orgánicos y muerte fetal. Estos hallazgos deberán confirmarse con estudios que involucren un mayor número de pacientes.

\section{BIBLIOGRAFÍA}

1. Farrell R, Ciarán K. Celiac sprue and refractory sprue. In: Feldman M, Friedman L, Sleisenger M, editors. Sleisenger and Fordtran's Gastrointestinal and Liver Disease. $7^{\text {th }}$ ed. Philadelphia: Saunders; 2002. p. 1817-41.

2. Schafer A. Thrombotic disorders: Hypercoagulable states. In: Goldman L, Ausiello D, editors. Cecil Textbook of Medicine. $22^{\text {nd }}$ ed. Philadelphia: Saunders; 2004. p. 1082-7.

3. Karoui S, Sfar S, Kallel M, et al. Antiphospholipid syndrome revealed by portal vein thrombosis in a patient with celiac disease. Rev Med Interne 2004; 25: 471-3.

4. Austin A, Campbell E, Lane P, et al. Nodular regenerative hyperplasia of the liver and coeliac disease: Potential role of IgA anticardiolipin antibody. Gut 2004; 53: 1032-4.

5. Shamir R, Shoenfeld Y, Blank M, et al. The prevalence of coeliac disease antibodies in patients with the antiphospholipid syndrome. Lupus 2003; 12: 394-9.

6. Makhdoom ZA, Randall NW. Dilated cardiomyopathy due to anticardiolipin syndrome in association with celiac sprue. J Clin Gastroenterol 2000; 31: 91-2.

7. Martinelli P, Troncone R, Paparo F, et al. Coeliac disease and unfavourable outcome of pregnancy. Gut 2000; 46: 332-5. 